\title{
On the English Teacher's Role in the Cooperative Learning Method
}

\author{
Zhen Zhou \\ Foreign Languages College, Nanchang Normal University, Nanchang, Jiangxi, 330032 \\ zoye100@sina.com
}

Keywords: English teaching; The learning strategy; The cooperative learning; The role of teachers; Coordinator; Inspiratory

\begin{abstract}
The theory of cooperative learning method originated in the USA and is considered to be the most important and successful teaching reform in recent years in China. And the new curriculum reform attaches much attention to students' all-round development and lifelong development. Only when the English teacher has a right awareness of their roles and becomes a coordinator, inspirator, collaborator, supervisor, organizer and estimator, the cooperative teaching would acquire the better implementation and students English efficiency can be boosted. The article attempts to offer some references for the English teaching in China.
\end{abstract}

\section{Introduction}

The theory of cooperative learning originated in the USA is considered to be the most important and successful teaching reform in recent years. But in our country, it is still a new and useful teaching theory and approach. However, many English teachers have misunderstandings of their own roles and do not take the teacher's role seriously in the cooperative learning. In our English class, many teachers are masters, graziers and authorities on the knowledge. This disobeys the new curriculum reform requirement of students' all-round development and lifelong development.

\section{The Concept of the Cooperative Learning Method}

The cooperative learning is that students engage in the learning activity in the group with obtaining reward on the basis of the performance of the team, in which students use these groups reasonably in the teaching progress so that they could work together to maximize their own learning and others' learning. The cooperative learning method claims that learning in groups is the main organization form of the classroom learning. According to the certain cooperation methods and procedures, the teacher helps students learn together in heterogeneous groups so as to promote students' cognitive, affective teaching strategy system. The cooperative learning is a kind of interactive learning method in which the group is a unit and each member of the group is responsible for the total task of learning and eventually it makes every member of this group successfully complete the task of learning.

\section{The Characteristics of the Cooperative Learning Method}

The characteristics of the cooperative learning method can be summarized as the following several aspects: a.The cooperative learning is a teaching activity that regards the small group activities as the main body; b. The cooperative learning is a teaching activity with mutual cooperation; c. The cooperative learning is a goal-oriented teaching activity; d.The cooperative learning is a teaching activity in which each team gains the reward after achieving the objectives in the teaching process; e.The cooperative learning is a learning task assigned by the teacher and teaching control process of teaching activities. 


\section{The Elements of the Cooperative Learning Method}

The Johnsons believed that there are five basic elements of the cooperative learning method. Only to meet the five elements, the cooperative learning is to be worthy of the name. The first element is the positive interdependence. In the cooperative learning, the team members should not only be responsible for the completion of their own learning tasks, but also responsible for the completion of taskd of the other group members. There are several types on this depending: a. Learning objectives are interdependent on each other. b. Rewards are interdependent. Performance evaluation is given according to three types of results: the total score of the group, the individual performance, the additional incentives provided when all team members approach a certain standard in the test. c. Positive interdependence of resources. Every member shares their resources to complete the learning task in order to achieve the group learning goals. The second element, namely, is the face-to-face interaction that requires students to make face-to-face communication. Students promote each other' s success in the cooperative learning. The third element is the personal responsibility, which requires each student not only to take on the assigned tasks, but also to bear the certain learning tasks. It requires a clear division of labor and the responsibility for every member. Having social skills is the fourth element and it requires teachers to guide students to master some necessary social communication skills so as to take on high quality cooperation. The fifth element is the group self-assessment which requires the team to periodically evaluate the situation of the cooperative learning, review activities of the team members and the extent of their respective roles to ensure the effectiveness of the group cooperative activities.

\section{The Significance of the Role of English Teachers in the Cooperative Learning Method}

English teachers should have a reasonable position of the role in the cooperative learning method so that the teachers can improve the quality of teaching, enhance the development of students, and build an efficient classroom.

To Promote the Growth of Teachers. The process of the cooperative learning is a whole organic one. If teachers want to guarantee the quality of teaching, teachers need to work on multiple projects before the scheme, such as making scientific and reasonable teaching designs, assuring the effective education managements, having timely feedback and adjustments. The effective implementation of teachers' reasonable position in the cooperative learning makes these activities work out. In the cooperative learning, these English teachers who can reasonably position their roles do not teach students things hand by hand, but help students cultivate the good quality of learning autonomously, improve the cultural level and basic skills, and cultivate the innovative spirit in the cooperative learning. In a word, reasonably positioning English teachers' role takes an important part for the curriculum reform and it is helpful in promoting the development of teachers so as to improve the teaching level and to make curriculum progress.

To Promote the Growth of Students. In the cooperative learning of English teaching, whether the teachers' role is a reasonably located depends on whether students are the main body in the classroom teaching. The subjectivity education theory can explain that reasonable teachers' roles take the important part in promoting the role of students' subject development. Therefore, English teachers would fundamentally promote the students' development only by reasonably positioning their roles. Primary and secondary school education play the basic parts for the lifelong development of students, as the foundation of buildings. Only to play the basic parts, English teachers can make students get a better development. So English teachers should focus on the development of students, and what they do are for students. English teachers can promote the students' development by positioning reasonably teachers' roles in the cooperative learning. If English teachers would not develop, students would not attain the better growth.

To Build a More Efficient Classroom. The reasonable orientation of English teachers not only helps to promote the reform and development of the new curriculum and makes the curriculum reform obtain a qualitative leap, but also stimulate English teachers to continually learn and grow. Besides, it is very helpful for the development of students' personality and social overall progress. The reasonable 
orientation of the role of English teachers determines whether the efficient English classroom can be built or not. In the cooperative learning, the teacher-student interaction reflects relationships between teachers and students and between students. Playing perfectly teachers' roles can fully reflect students' role interactions. Only under this premise, can students show a positive behavior and communicate effectively with others so as to optimize the teaching effect in the classroom. On the contrary, if it is not good, it may make the classroom effects weaken or even invalid. Therefore, the English teachers must play the good role to create a more efficient classroom.

\section{The Reasonable Teachers' Role in the Cooperative Learning Method}

Coordinator. Because there are objective differences in the foundation, ability and non intellectual factors among students, when English teachers are constructing these cooperative learning groups, they not only take the match of different cognitive level among students, but also other non intellectual factors, such as their hobbies, personalities, emotions with constructing these cooperative learning groups to engage in learning activities together and complete tasks of learning. At the same time, English teachers should also pay attention to coordinating their relationships, guiding team members to establish mutual trust, good interpersonal relations and creating a harmonious and pleasant learning environment.

Inspirator. The students' cooperative learning activity itself is a process from passive to active, inspiring to autonomous, and it requires English teachers to be good at inspiring students to participate in these cooperative learning activities and experience the joy via various incentive means. Its aims are to improve students' abilities of solving practical problems by using language. German educator Diesterweg said that the amazing teaching skills virtually are not the art of education. Instead, encouraging, awaking and inspiring are the true arts of education. The proper and great encouragement from English teachers could promote the growth of the individuals in many aspects, for instance, the knowledge, ability and thinking. It would be of great significance in improving students' lifelong learning habits and abilities.

Collaborator. The teaching process does not only imply that English teachers impart the knowledge and experience to students via the teaching materials, but English teachers and students work together to explore new knowledge in the interpersonal process. English teachers are not only organizers of learning activities, also important partners of students. By taking part in and discussing issues, exchange ideas, and finishing cooperative learning activities with students, English teachers play a major role in three aspects: Firstly, they take fully advantages of students' strengths and overall functions by decreasing the both sides' psychological distance; Secondly, they help students find the right courses with the timely intervention; Thirdly, it is helpful to form the harmonious teaching situation by communicating with students.

Supervisor. The classroom is a place in which English teachers provoke students to think and provide students with a number of opportunities to make practical applications. In the cooperative learning, students mainly make speaking activities. English teachers should pay attention to observing, participating, patroling and guiding students so as to monitor the process of students' speaking activities. Only by focusing on students' responses, giving the full affirmation and encouragement to student timely when they question and helping and inspiring them as students have problems, and English teachers can ensure the cooperative learning effectively be promoted.

Organizer. The modern education deems that at present, one' study style at school must maintain a certain internal consistency with his future lifestyle. Besides, the cooperative learning exactly acts as a starting point of that consistency. As the designer of the classroom teaching activities, English teachers should break up the traditional "nursery desk" arrangement, and take students" individual characters and their personal requirements of study into full consideration during the organization of group study activities. What's more, in order to give the students more opportunities to speak and take part in the language activities and give full play to their own individual differences, teachers should also guide students to think and communicate from multiple aspects and levels. Besides, after having the team members' intentional or unintentional help, students' confidence in English study is enhanced. The organization is used in the intersection of the old and new knowledge. Students tend to have more desire 
to explore new knowledge. The group discussion can make students understand the language, activating the demand of students' desires so as to achieve a better effect.

Estimator. The effectiveness of the cooperative learning depends greatly on the application of the evaluation mechanism. English teachers must abandon the traditional curriculum evaluation systems which centers on the students' scores, putting more emphasis on the meaning and value of study itself, adopting diverse means, such as teachers' evaluation, self-evaluation of students, students' mutual evaluation and so on. What's more, the timely and objective evaluation on the result of study is also very important for teaching and learning, and the evaluation on the study process and result should be united. And the evaluation on the group team should combine with the evaluation on the team members, and some encouraging evaluation which develop students' team spirits and cooperation should also be adopted. Particularly, in the course of assessment of the completion of group learning tasks, teachers should adopt encouraging evaluation, incentive evaluation, and competitive evaluation in order to promote every student's development.

\section{Conclusion}

Nowadays the cooperative learning mode is a classroom teaching organization form which is important and has the broad application prospect. And it has achieved the certain results in the practice of English teaching. As an English teacher, one should be clear about his role in the cooperative learning with the comprehensive understanding. The teacher should make the combination of playing the leading role and arousing students' enthusiasm in order to create a good language environment for students at different levels. And it can make students really share knowledge resources and ways of thinking so as to achieve a better teaching effect.

\section{Acknowledgements}

This work was supported by the 2012 key project of educational science planning of Jiangxi Province (Project name: The exploration into the training mode of rural backbone teachers in the primary and middle school of "The national planning" in Jiangxi Province, 12ZD012); 2105 high quality resource sharing course "English teaching and research" of Nanchang Normal University.

\section{References}

[1] Bailey K. M., A. Curtis \& D. Nunan. Pursuing Professional Development: The Self as Source[M].Boston, MA. : Heinle \& Heinle. 2001.

[2] Johnson D.W. \&Johnson R.J Learning Together and Alone: Cooperative, Competitive, and Individualistic Leaming [M]. Boston: Allyn \& Bacon, 2004

[3] Mingming Chiu. Adapting teacher interventions to students needs during Cooperative Learning. How to improve students problem solving and time On-Task. American Education Research Journal Summer[J]. 2004, 41(2): 365-399.

[4] Ning Tian. The research of application of the cooperative teaching method in the junior middle school. English teachers[J]. 2016, 16(5): 121-123.

[5] Penny Ur. A Course in Language Teaching: Practiceand Theory [M]. Cambridge: Cambridge University Press, 2000.

[6] Richards J. C. \& T. C. Farrell. Professional Development for Language Teachers[M]. New York: Cambridge University Press. 2005.

[7] Ruiqing Xin. Cooperative Learning and TEFL to Non-English Majors in Vocational Colleges[J].Education and teaching research. 2013, 27(6): 
[8] Slavin,R.E. Cooperative learning and cooperative school [J]. Educational Leadership, Aaronson, E. The Jigsaw Classroom[M].Beverly Hills, CA:Sage Publications, 1978.

[9] Sharan,Y.\& S. Sharan. Expanding Cooperative Learning through Group Investigation[M]. New York: Teachers College Press, 1992.

[10] Vermette P. J Making Cooperative Learning Work: Student Teams in K-12 Classrooms[M]. New Jersey: Prentice-Hall, 2001(12):45. 